\title{
ENTREVISTA A JUANA ESCABIAS, DRAMATURGA Y \\ DIRECTORA DE ESCENA ${ }^{1}$
}

\author{
Milagro Martín Clavijo²
}

Juana Escabias nació en Madrid. Es dramaturga, directora de escena, docente e investigadora teatral, fundadora de la compañía Teatro Sonámbulo (2003) y Presidenta del Comité de Teatro de UNESCO CM, entidad desde la que organiza varias actividades internacionales relacionadas con el teatro. Ha impulsado proyectos de exhibición teatral y de edición, coordinando con el Ministerio de Asuntos Exteriores de España / Instituto Cervantes / AECID y UNESCO la promoción del teatro español de autores vivos a escala universal.

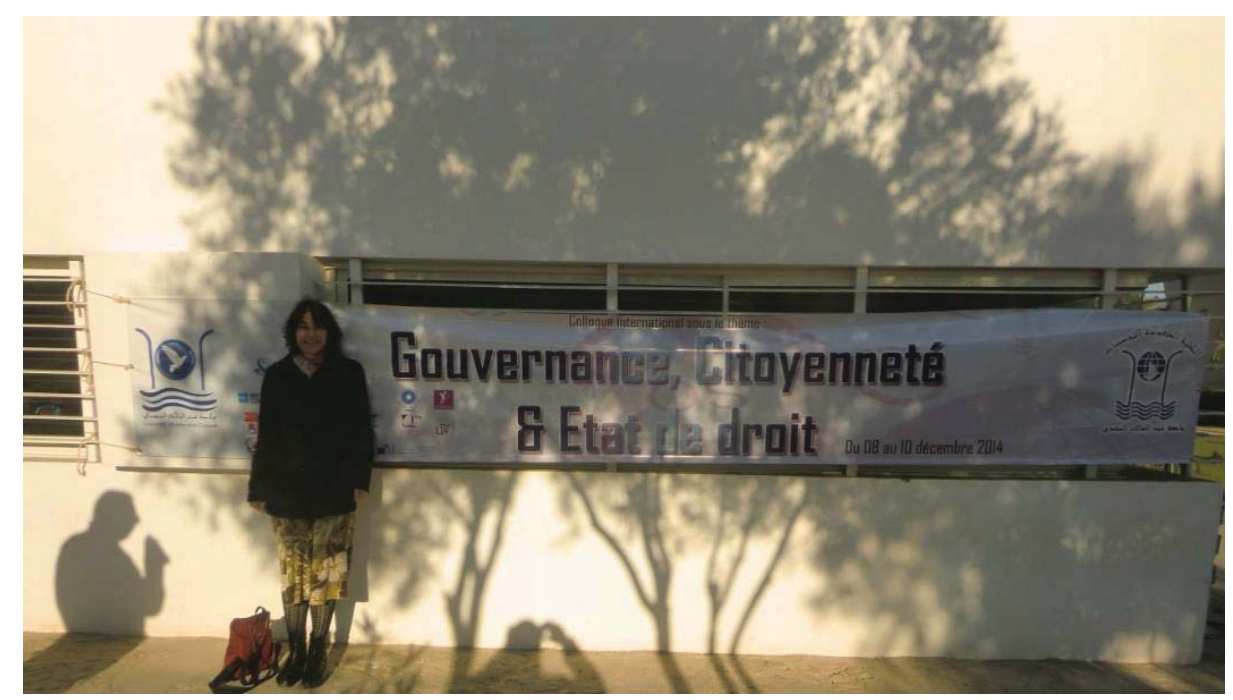

En Tetouan, en el Congreso del Grupo de Investigación "Escritoras y Escrituras", celebrado en diciembre de 2014.

\footnotetext{
1 Fecha de recepción: 17/06/2014.

Fecha de aceptación: 30/07/2014.

2 Profesora Titular de Universidad, Departamento de Filología Moderna, Universidad de Salamanca, Salamanca, España; $\bowtie$ mclavijo@usal.es.
} 
Es Licenciada en Ciencias de la Información/Comunicación/Periodismo (Univ. Complutense) y Doctora en Filología (UNED). Posee formación en dirección de escena e interpretación. Trabaja como profesora de Arte Dramático en Madrid, ha impartido clases sobre esta disciplina en diversas universidades españolas y extranjeras, y pertenece a varios grupos internacionales de investigación teatral y literaria, entre ellos "Escritoras y Escrituras".

Es autora de 18 obras teatrales largas y de numerosos textos teatrales breves, así como de varias novelas y colecciones de relatos. También es autora de adaptaciones de dramaturgas españolas del Siglo de Oro. Entre sus obras dramáticas, destacamos Tierra Convexa "Premio Autores con Margarita Xirgu 2008", Apología del amor "Premio El Espectáculo Teatral 2010" e Historia de un imbécil (finalista del Premio Nacional de Literatura Dramática 2010). En 2013 obtuvo el Premio Extraordinario de la UNED por su investigación "Dramaturgas del Siglo de Oro".

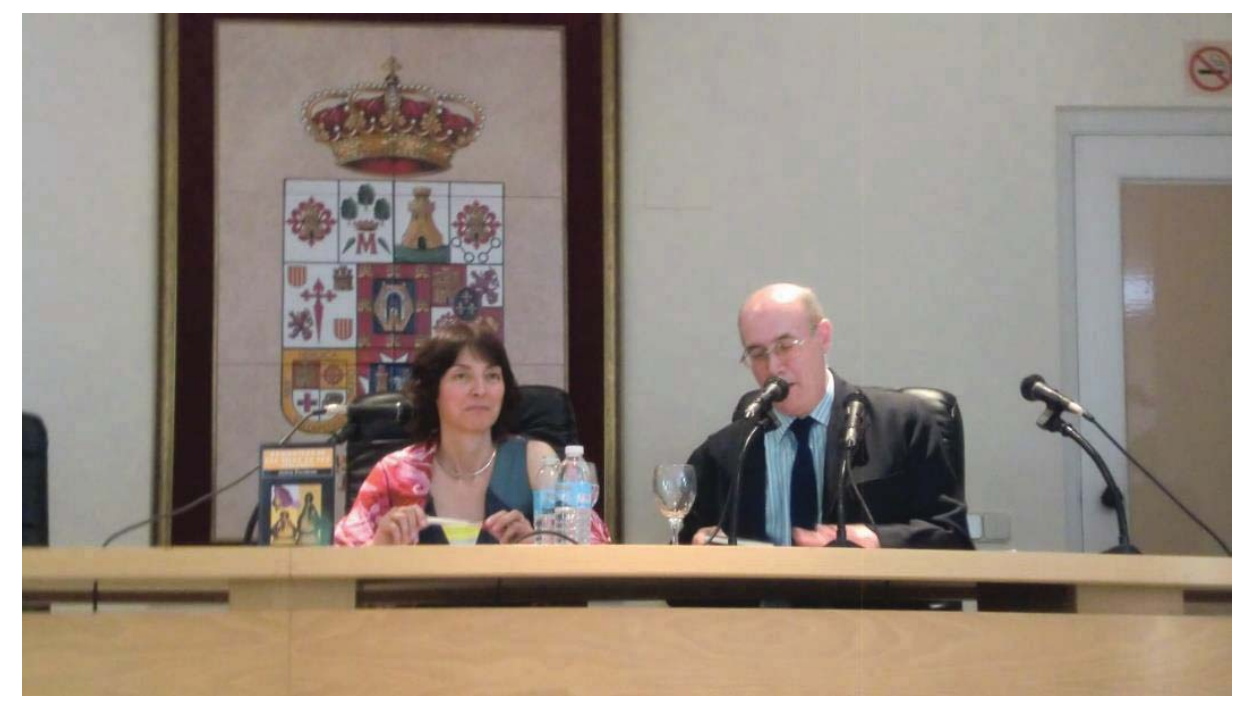

En Almagro, junto a Felipe Pedraza, presentando su libro Dramaturgas del Siglo de Oro.

Como autora y directora de escena sus trabajos se han mostrado en diversos escenarios, entre ellos: Sala Manuel de Falla de la SGAE, Corral de Comedias de Alcalá, Teatros del Canal, Teatro Fernando de Rojas (Círculo de Bellas Artes), La Casa Encendida, Teatro Guindalera, Teatro Lagrada, Teatro Affratellamento (Italia), Aula 
Battilani de la Universidad de Florencia, Naves de El Español-Teatro Español (MataderoMadrid), etc.

Sus textos teatrales han sido editados en diversas editoriales, entre otras: Ediciones CÁTEDRA, Editorial CASTALIA, Revista ESTRENO, VISOR Libros, Ediciones Irreverentes, Huerga y Fierro Editores, Editorial Endymion, Biblioteca Virtual Cervantes, Asociación de Autores de Teatro, etc.

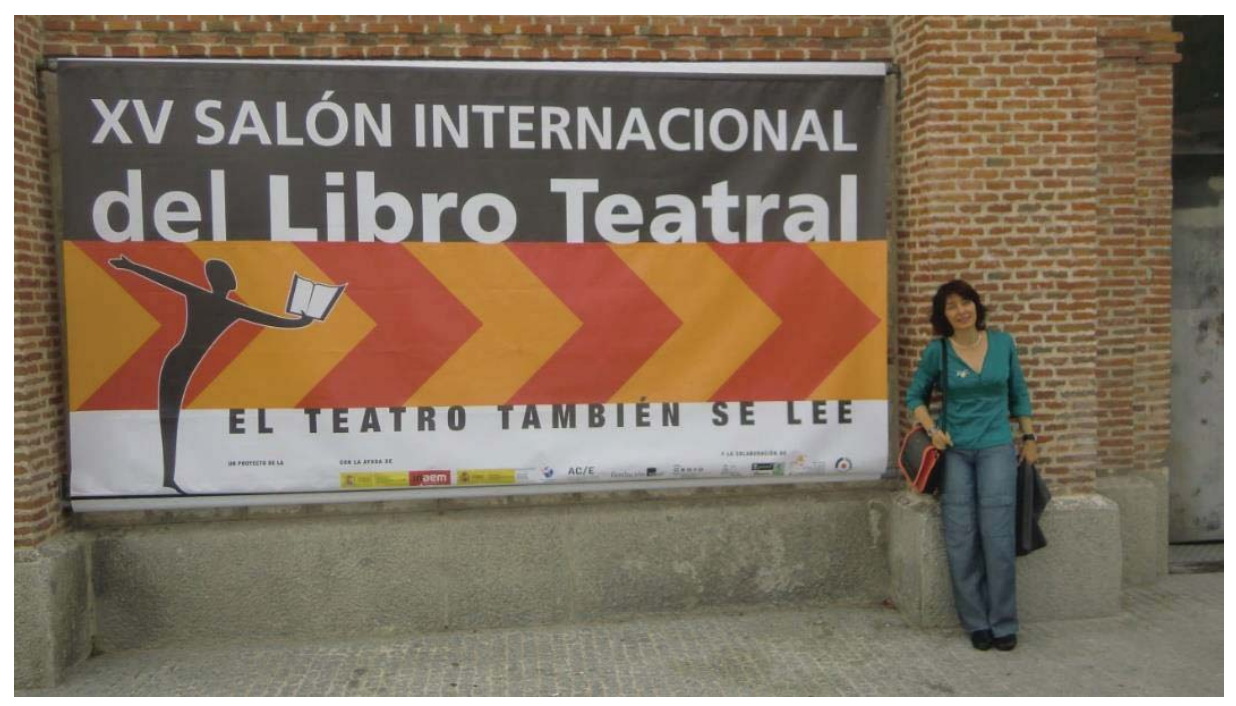

En el último Salón Internacional del Libro Teatral.

Sus últimos estrenos han sido los siguientes: En horario de oficina, escrita junto a Juan Carlos Rubio y Blanca Doménech para ser representada dentro del FESTIVAL FRINGE 2014; y Mujeres Infieles, programada en el Festival SURGE MADRID 2014.

En breve saldrá al mercado la traducción al inglés y al italiano de dos obras de la autora, La puta de las mil noches (en Estreno Contemporary Spanish Plays $n^{\circ} 35$, New York. Traducción de Patricia O’Connor) y Nove donne infedeli (en Editorial ARACNE: Roma) 
Podríamos comenzar esta entrevista con una presentación personal de la dramaturga. ¿Cómo se ve Juana Escabias?

Me cuesta hablar acerca de mí misma. Pero en muchas entrevistas me han pedido que lo hiciera, y ya voy acostumbrándome. Juana Escabias es a la vez alegre y reflexiva. Tengo un desarrollado sentido de la responsabilidad. Me gusta trabajar y me gusta mi trabajo; es algo que siempre busqué de forma premeditada: trabajar en lo que me apetecía. Lo he conseguido durante toda mi vida, en ese sentido me siento afortunada. Soy solidaria con el mundo en el que habito y deseosa de lograr una sociedad más justa allá por donde paso. Estoy apasionada con el hecho de estar viva y con todo lo que emprendo, enamorada de la escritura como actividad y del teatro como escritura y realidad escénica. Siempre he preferido la libertad a la seguridad, conocer mundo, moverme por el mundo, aprender de las sociedades y civilizaciones desconocidas, de seres humanos muy distintos a mí misma. En el pasado trabajé como periodista, he cruzado en solitario países africanos, sudamericanos y árabes, he presenciado guerras y conflictos armados de menor envergadura, grandes hazañas y acciones miserables, y he conocido a multitud de personalidades y a infinidad de seres anónimos que me han impresionado y me han enseñado mucho. Desde 1999 vivo del teatro, en el que he pasado y pisado por todos sus registros: dramaturga, directora escénica, fundadora de una compañía, gestora de proyectos, editora de libros, promotora de teatros, profesora... Ahora atravieso la etapa más feliz de mi vida, en mi infancia y adolescencia me sentía un bicho raro: no deseaba lo mismo que los niños y niñas ni los chicos y chicas de mi barrio ni de mi instituto, no quería casarme y recluirme en un hogar sino recorrer el mundo, no quería entramparme con la hipoteca de un chalet sino disponer de tiempo libre para escribir, no quería un trabajo estable que me obligara a ir todos los días al mismo aburrido lugar sino una forma de ganar un sueldo que enriqueciera mi espíritu y me permitiera desarrollar mi profesión en diferentes sitios, no quería tener a mi lado un novio o marido al que tuviera que pedirle permiso hasta para respirar... Afortunadamente he conseguido realizar todos esos deseos. Es duro ir a contracorriente, pero te ofrece muchas recompensas. Una de las mayores recompensas que me ha traído la vida ha sido conocer a mi marido, Santiago, un auténtico "compañero de viaje". 
Vivir del teatro a día de hoy no puede resultar nada fácil, a pesar de la versatilidad que ha demostrado siempre. ¿Cómo ha conseguido sobrevivir?

En la España del siglo XXI es complicadísimo. La crisis nos castiga. Por otro lado, quienes hacemos cultura estamos recibiendo un escarmiento político por parte del actual gobierno: que considera la cultura y el librepensamiento enemigos personales. La subida del IVA decretada por el gobierno de Mariano Rajoy ha sido un varapalo en toda regla. Que el teatro español tenga que soportar un tipo de IVA más elevado que el fútbol es un atentado contra la industria cultural, contra quienes luchamos por vivir con dignidad de esta ocupación artesana que es el Arte y contra el propio progreso humano. La medida provocó desde sus inicios que se suspendieran bastantes producciones que ya estaban previstas y una notable reducción en el número de futuros proyectos. A la contracción del mercado se unen los drásticos recortes en subvenciones y contrataciones públicas. Para las compañías, encontrar un escenario o conseguir una función es una hazaña. En ese desolador mercado los autores tenemos cada vez menos posibilidades de estrenar nuestra obras. Hoy, más que nunca, recordando a Mariano José de Larra, escribir en España es llorar. Pero como lo nuestro es vocacional (por lo menos en mi caso) y la vocación se incrusta en cada célula hasta volverse genética, continuaremos luchando y escribiendo, y en la medida de lo posible representando. En medio de ese oscuro panorama, encuentro que la salud de nuestra "dramaturgia" es extraordinaria. Yo, que por mi profesión y por necesidades del alma veo y leo teatro español, sé que en España, en la actualidad, se escribe mucho buen teatro. En tiempos difíciles, la imaginación, el deseo de superación y adaptación al medio hacen milagros. Continuamos adelante reduciendo costes y autoexplotándonos aún más que unos años atrás. Se sobrevive con dignidad y por amor al teatro, pero en condiciones lamentables. 


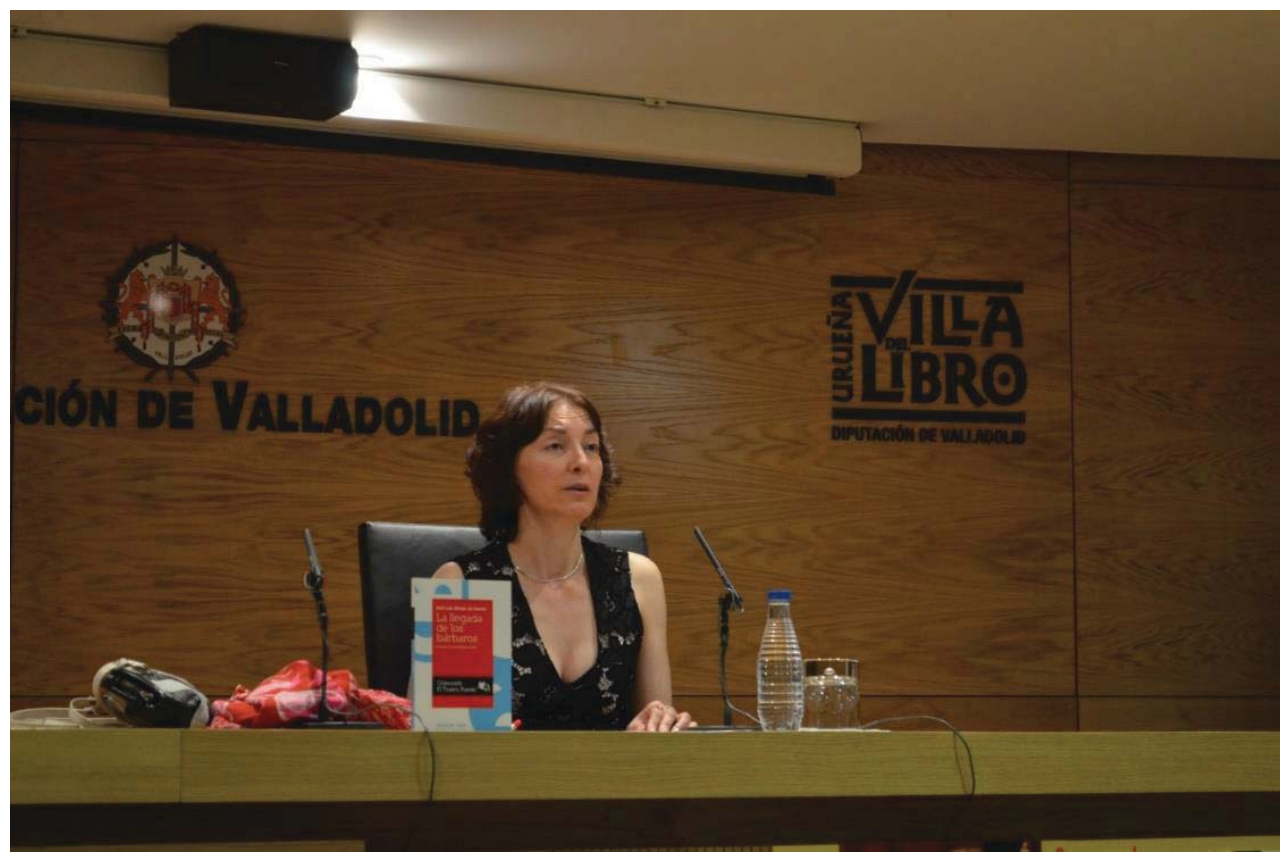

En Urueña, la Villa del Libro, impartiendo una conferencia.

En medio de este panorama que nos ha trazado del teatro actual ¿qué espacio poseen las mujeres? ¿Se puede hablar de un espacio de paridad para las dramaturgas españolas?

Las mujeres continúan ganando presencia en el sector de forma paralela a la que han venido avanzando en toda la sociedad, pero el teatro continúa siendo terreno masculino, sobre todo si hablamos de creación y no de interpretación. Si establecemos una comparación con otros sectores artísticos, por ejemplo la novela, las dramaturgas tienen un largo camino por recorrer. Las estadísticas son optimistas y aseguran que en las últimas generaciones las mujeres escriben teatro en igual proporción que los hombres, pero los escenarios estrenan de forma abrumadora a los autores, y no a las autoras. Junto a este fenómeno convive el de los premios. Las dramaturgas españolas, a igual grado de veteranía, curriculum, proyección y reconocimiento por parte del mundo del teatro, poseen menos premios teatrales que los dramaturgos. En el sector escuchas a menudo "las voces femeninas interesan", pero la presencia escénica de las escritoras es ínfima. Yo soy optimista, el camino todavía está plagado de lagunas y escollos y podrá desarrollarse a más o menos velocidad, pero no tiene posible vuelta atrás, las dramaturgas terminarán por conquistar la escena. 


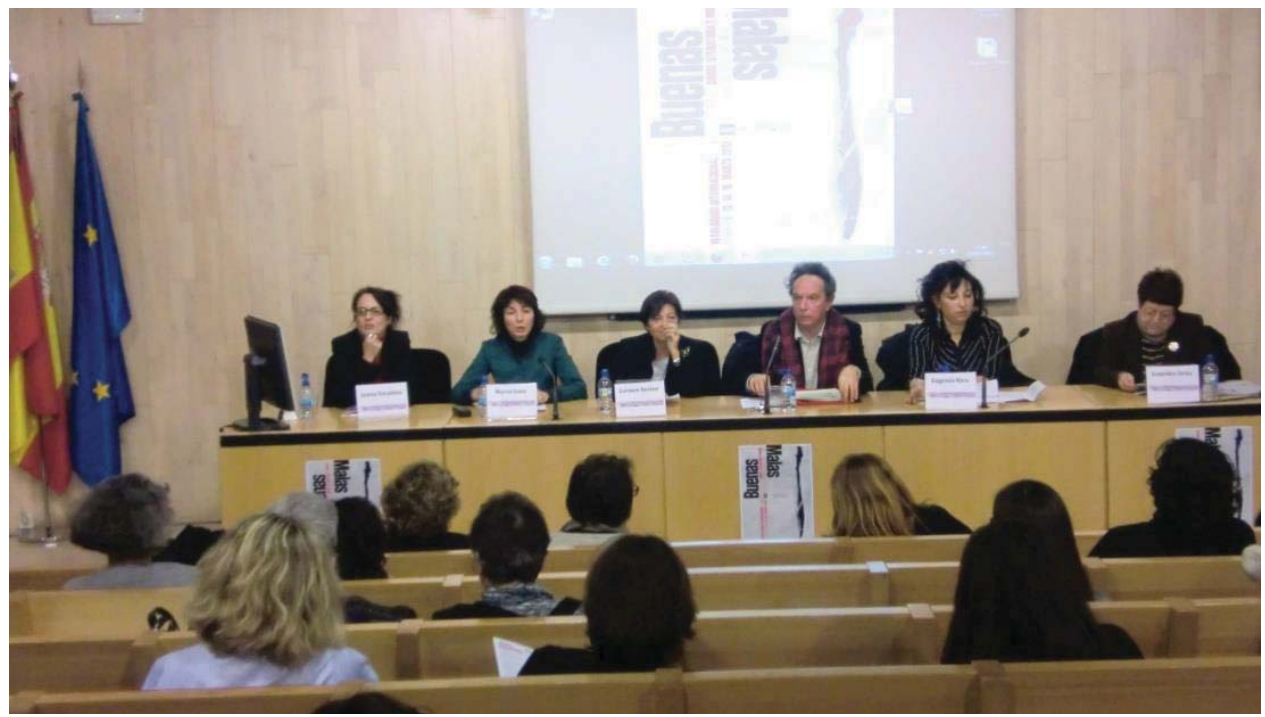

En la UNED, el 8 de marzo, en una mesa de escritoras.

\section{¿Por qué cree que se producen tales reticencias? ¿Cuáles serían las causas?}

Por inercia del pasado, por miedo a la competencia y a la novedad, y porque siguen existiendo reductos asociativos y personas particulares que consideran que la escritura femenina es, de forma general y sistemática, inferior a la de los hombres, como lo es su pensamiento y capacidad. A esas personas y sectores no les interesa el trabajo de las dramaturgas porque su mirada les resulta insólita y desconcertante o porque abordan cuestiones que para ellos no son relevantes. Es un lenguaje distinto, al que nadie les ha habituado, y que a veces les incomoda. Y de forma inconsciente, continúan torpedeando la creación femenina y obstaculizando su difusión y consolidación. En mi opinión son los últimos vestigios de una educación retrógrada que ha castigado a varias generaciones de españoles durante demasiado tiempo.

\section{Ese es el panorama actual y sus causas, pero hablando ya explícitamente de su} producción, ¿en sus obras teatrales se refleja esa desigualdad?

Pertenezco a una generación que ha vivido y exigido la igualdad como derecho innegable, como algo que me correspondía por el simple hecho de pisar el mundo, pero en mi obra siempre están presentes las mujeres obligadas a vivir una existencia de 
segunda categoría por el hecho de pertenecer "al segundo sexo". Yo misma, en demasiadas ocasiones, he podido probar en carne propia el amargo sabor de esa experiencia. Mi memoria es denuncia y al mismo tiempo homenaje a aquellas que nos antecedieron, aquellas a quienes debemos agradecer que nosotras, las mujeres del siglo XXI, sintamos la igualdad como derecho innato. Las protagonistas de mis obras Cautivas o España 1940, presas políticas de las cárceles franquistas, servirían de ejemplo de ese modelo de mujer, como lo sirve Carla, personaje de la obra coral Interiores, criada en la posguerra española y castrada social e intelectualmente para alimentar los usos y costumbres de esa época. Otro modelo de mujer cercenada es Bianca, de Tierra convexa, con sobrados merecimientos profesionales como para ascender, pero que no consigue que los hombres que la rodean la contemplen más que como un objeto para saciar sus apetitos sexuales.

Es evidente en su teatro el discurso a favor de los derechos humanos más básicos, sobre todo en el caso de la mujer. ¿Nos podría explicar cómo lo lleva a cabo?

Mi feminismo se engloba en un discurso progresista más genérico a favor de los derechos humanos fundamentales, de la igualdad y la justicia como motor de la vida, de la libertad y la autorealización en contra de cualquier tipo de discriminación, represión o involución. La protagonista de Tu sangre sobre la arena, por ejemplo, no ha nacido en Europa, sino en ese Tercer Mundo en el que ser mujer resulta aún más tétrico: su discriminación se multiplica a consecuencia de la pobreza. Otro de los personajes de Interiores es un homosexual obligado a ocultarse durante años, y que ahora reivindica ante su hijo su condición y su derecho al amor. La homosexualidad vivida como problema por sus protagonistas en un mundo todavía estrangulado por los clichés y la represión es un tema presente en otras de mis obras, como Ícaros, Islas o El sucesor. En Esbozo sobre una teoría de las emociones, sin embargo, el análisis del amor homosexual se centra en una pareja estable y aceptada por su entorno social y familiar que reproduce los errores y miserias de muchas parejas heterosexuales: chantaje emocional, celos, control abusivo de la libertad del otro... 


\section{Como autora teatral, ¿cuáles son sus temas recurrentes o preferidos?}

Uno de los temas que más me preocupa es la incomunicación entre los seres humanos, la imposibilidad de llegar los unos a los otros, las dificultades para comprenderse y la soledad que esa circunstancia genera en todos nosotros. Mis grandes temas, aquellos que con más frecuencia se cuelan en mis escritos, son la hipocresía social $\mathrm{y}$ todo ese repertorio de dificultades que padece el ser humano para vivir de forma plena en sociedad, con el miedo como piedra angular de muchas de ellas. La dificultad para entenderse con el prójimo, para llegar a otros, incluso a nuestras parejas o familiares más próximos, aparece y reaparece en casi todas mis obras, como puede apreciarse en Vias férreas, Hojas de algún calendario, Islas, Esbozo sobre una teoría de las emociones o Fotogramas... La violencia también es una constante en mi teatro, no solo la agresión física o sexual ejercida de forma directa sobre alguien (temática sobre las que se cimentan entre otras Fantasmas, Deseo o Apología del amor) sino también la violencia innata a la lucha de clases y a la promoción social que nos convierte en depredadores de otros seres humanos a través de primitivos instintos de supervivencia camuflados bajo académicas denominaciones como la ambición. Voracidad de los parques contiene un buen muestrario de esa violencia racionalizada y aplaudida por la sociedad. Mi propuesta global como artista es hacer reflexionar al lector/espectador, colocarle delante de los ojos las grandes cuestiones del hombre de todos los tiempos para sacudirle y hacerle crecer. Descolocar a la gente, no trabajar desde el tópico y cambiar continuamente de perspectiva son una parte de las técnicas que conforman la esencia de mi escritura. Haciendo pensar a los demás consigues que sus mentes se abran y crezcan. La experimentación formal también es una constante en mí. Que el arte haga progresar el mundo: nuevos lenguajes para traer nuevas temáticas.

¿Cómo reacciona el público teatral español ante esa experimentación tanto temática como formal? ¿Cuáles son las preferencias de nuestro público a día de hoy?

Cuando yo comenzaba en el oficio de la escritura dramática, un veterano dramaturgo amigo mío, excelente escritor y persona, me dijo algo que yo entonces no entendí: "A la gente le gusta que en el teatro le cuenten lo mismo que le cuentan los 
periódicos y la televisión". Él lo manifestaba lamentándose, opinaba que era perjudicial para el sector y para los artistas que el teatro, para ser considerado buen teatro, tuviera que ser "rabiosa actualidad". Ahora, con mi experiencia en el oficio, me he dado cuenta de cuánta verdad escondían sus palabras, y de que cuando un dramaturgo apuesta por crear obras que profundicen en la esencia del ser humano de todos los tiempos, reflexionando sobre las cuestiones más profundas que atañen al hombre y a su realidad intangible, encuentras más dificultades para abrirte camino que con obras que se "agarran" a la actualidad. La atemporalidad paga ese incomprensible peaje.

\section{¿Ha escrito también teatro histórico?}

Intento escribir teatro atemporal, que no es lo mismo. Prácticamente no poseo teatro histórico, las ya mencionadas Cautivas y España 1940 constituyen excepciones en mi producción. Cultivo un tipo de teatro en el que el escalpelo se adentra en el subsuelo para explorar los grandes enigmas de la vida que anteceden incluso a las cuestiones más transcendentales del hombre de todos los tiempos. Mis preguntas rebasan el consabido qué somos de dónde venimos o a dónde vamos para tornarse aún más primigenias: ¿por qué hay algo en lugar de nada? En Historia de un imbécil, en la que el protagonista es la telebasura, la reflexión de fondo se centra en el poder de los mass media no solo para manipularnos ocasionalmente, sino también para conformar nuestro propio pensamiento y el de nuestros descendientes en aras del adocenamiento y la eliminación de la conciencia. Tierra convexa, ambientada en Estados Unidos durante las primeras emisiones de la televisión comercial, ya contenía esa reflexión.

\section{Juana, en la actualidad ¿por qué una autora se decide por la escritura teatral?}

\section{¿Cómo ha llegado a escribir teatro?}

Era una niña cuando comencé a escribir. Escribo desde la edad de nueve años, pero mi aterrizaje en el teatro no se produjo a una edad precoz. Desarrollaba mi creatividad en la narrativa. Un día, súbitamente, descubrí el significado del teatro. Un día, de manera repentina, descubrí que la novela es un producto cultural de la sociedad moderna, de la 
mentalidad de un hombre alimentado por siglos y más siglos de civilización. En el teatro, sin embargo, perdura la mentalidad de los primeros hombres; su forma sobrenatural de pensamiento subsiste en los conflictos, a su manera símiles de fósiles. Ese descubrimiento me atrapó. Desde ese día vivo para escribir teatro.

Me imagino que en su extenso recorrido por el mundo del teatro no habrá estado sola ¿Pertenece a alguna asociación profesional de dramaturgas?

Soy miembro del Grupo Internacional de Investigación Escritoras y Escrituras, y también del Seminario Permanente Sobre Literatura y Mujer (Siglos XX-XXI). Ambas iniciativas son dos extraordinarias plataformas internacionales para la investigación literaria y dramática y para la promoción del trabajo creativo femenino. También soy miembro de la Asociación de Autores Teatrales y presido el Comité de Teatro de UNESCO C.M. El asociacionismo me parece necesario, la hermandad crea progreso y beneficio para todos. En relación con la dramaturgia femenina siempre he realizado una "militancia activa" en diferentes terrenos. Cuando he trabajado en salas de teatro y he tenido potestades organizativas he apoyado la programación de autoras, impulsando diversos proyectos. En el campo de la edición, cuando he poseído capacidad de decisión, también he defendido la presencia de las dramaturgas. Cito como ejemplo la colección El Teatro Puede, en la que esa presencia femenina llegó al 50\%.

En su trayectoria ha mostrado a menudo su capacidad para conjugar escritura y producción de sus propias obras. ¿Es difícil hacerlo? ¿Cómo lo ha conseguido?

Es casi obligatorio conjugarla, porque la narrativa es un oficio que se perfecciona escribiendo, pero la escritura dramática, por el contrario, hay que aprenderla y perfeccionarla vinculada a un escenario. Tienes que saber si tus obras funcionan "dramáticamente", y esa experiencia solo te la proporciona trasladar tus textos a montajes escénicos. Si logras que algún tercero monte tus obras, la experiencia puede ayudarte a mejorar como dramaturgo. Pero para mí, la experiencia más válida de todas consiste en dirigir. Dirigir te enseña las claves de la escena, a dominar el ritmo, a ponerte en el lugar 
de lo que necesitan los actores y a aprender a pensar desde su punto de vista (y por lo tanto desde el de los personajes), a dosificar las estructuras, a darle prioridad a la acción dramática por encima de todo, a crear coherencia en un texto dramático, a crear tensión, a no ser artificioso, y a que las cosas (en las obras que escribes) sucedan unas a consecuencia de otras, y no unas después de otras. No "dominar la perspectiva escénica" provoca (lo he visto en muchos espectáculos profesionales) que el espectador vea en escena los objetivos del autor/escritor, pero no los objetivos de los personajes, que son los que hay que ver.

\section{Seguramente por ese motivo se decidió a fundar su propia compañía.}

Efectivamente. Por ese motivo fundé la compañía Teatro Sonámbulo, para experimentar sobre la realidad del escenario, para experimentar con nuevas formas, para hablarle, como Chejov deseaba, a todas las almas. La fundé en el año 2003 con el objetivo de experimentar escénicamente y adquirir experiencia en ese sentido. A través de esa plataforma se han llevado a escena varios de mis textos (dirigidos por mí o por otros profesionales) y también se han dirigido espectáculos con textos de otros escritores. La aventura va a continuar, porque la escena también te permite ensayar nuevas formas textuales. En los últimos tiempos, varios profesionales se han unido a la compañía. A mí me gusta hacerla funcionar como un grupo de trabajo. Veteranos directores de escena como Juanjo Granda, directores de escena y de cine y a la vez dramaturgos con una inmensa valía artística, como Rafael Gordon, y actrices y directoras como Adriana González-Borgas se han incorporado al grupo. Es una oportunidad extraordinaria verlos desarrollando su trabajo, aprender de ellos, colaborar con ellos. Su talento me arropa y me hace crecer. Compartir experiencias con ellos constituye un regalo. 


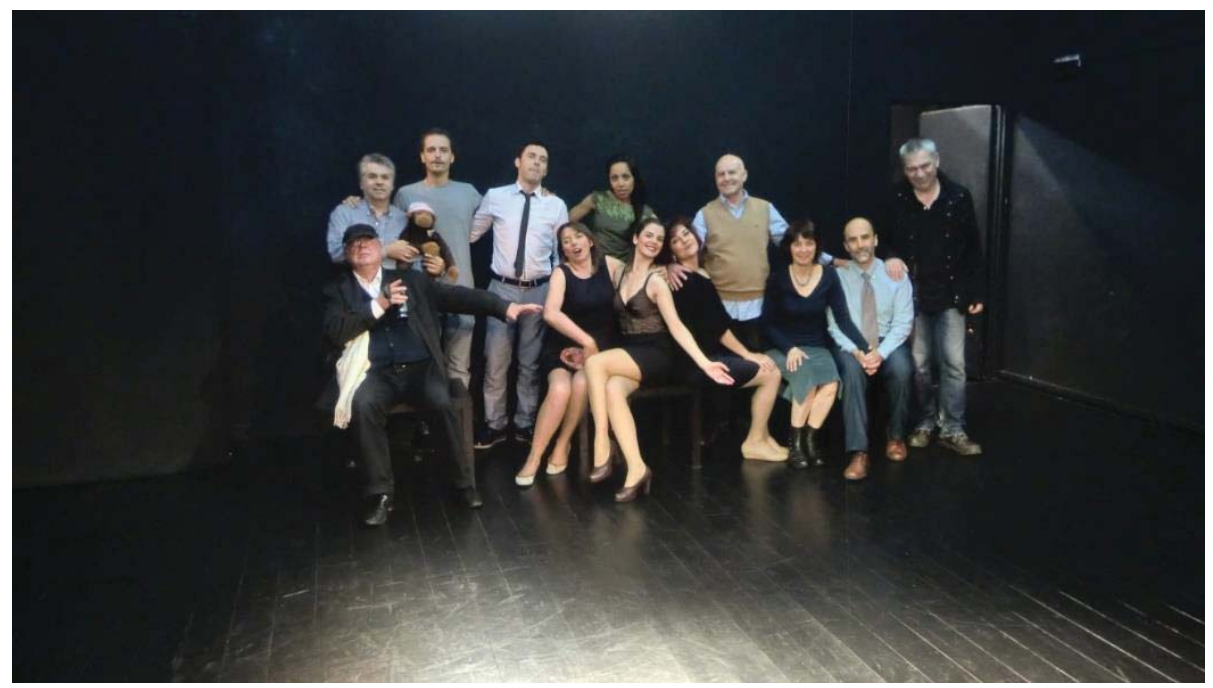

Con miembros de la compañía Teatro Sonámbulo.

Me resulta muy interesante el hecho de que complemente su labor como creadora con la docencia. Realmente ¿son compatibles esas dos actividades?

La docencia es una forma segura de sustento para muchos creadores. En mi caso, enseño teatro, lo que supone un privilegio, porque enseñando teatro aprendes teatro. Trabajo como docente teatral de forma continuada desde el año 2002. He impartido cursos de escritura, interpretación, dirección y teoría teatral en numerosos centros y universidades. Una de mis últimas experiencias ha sido en Guinea Ecuatorial, teniendo como alumnos a directores y actores veteranos. Trabajábamos en puestas en escena con un texto prefijado en un mundo dominado por la narración oral. Fue magnífico. En el terreno teatral también he trabajado en salas de teatro, como responsable de promoción y prensa. También he desempeñado tareas de programación y organización de ciclos teatrales. Ese trabajo te ayuda mucho a conocer al destinatario de tu trabajo, el público y el mercado. 


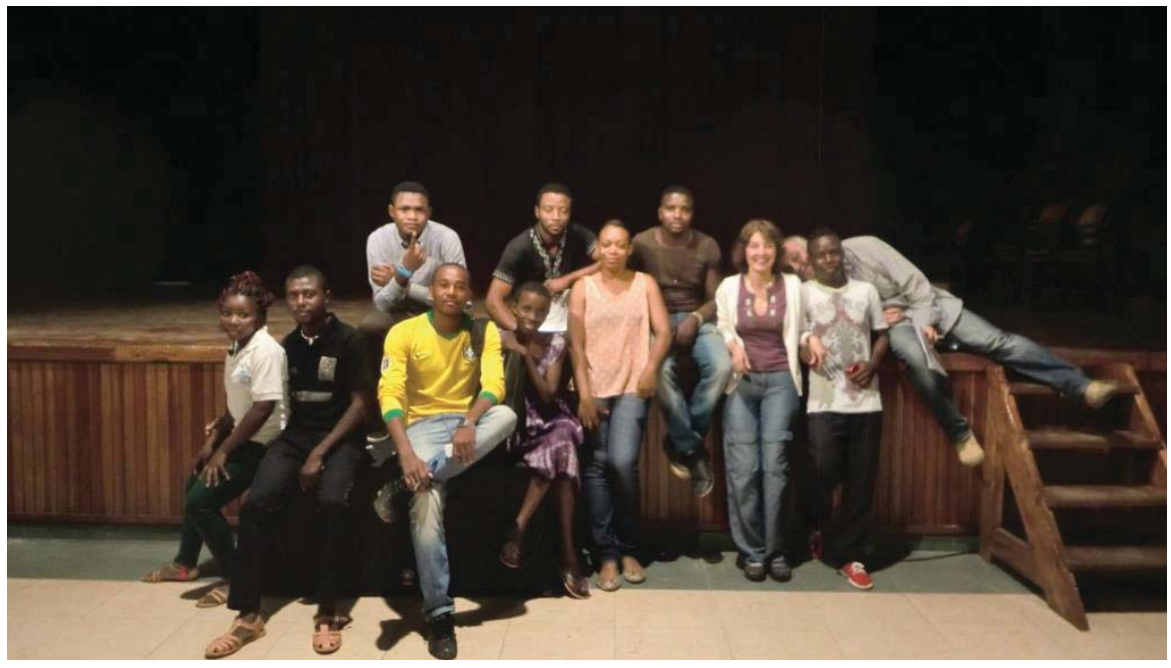

En Malabo, con los alumnos de un curso de Dirección Escénica.

Su teatro se ha calificado de simbólico ¿Cómo se manifiesta la presencia de componentes simbólicos en sus obras?

El simbolismo en mis obras es constante. Me viene a la cabeza El sucesor en la que la acción dramática se desarrolla en un aeropuerto: cruce de caminos en el que dos hombres (antiguos compañeros de colegio que vivieron una mutua atracción sentimental) se encuentran al cabo de los años, para volver a tener una segunda oportunidad de recobrar los sentimientos del pasado y hacer renacer lo que en el pasado no llegó a ser. Esta simbología de una terminal de transportes (lugar de paso por excelencia y de despedidas) también está presente en Vias férreas, historia de un desencuentro sentimental entre un hombre y una mujer en un hotel cercano a una estación de tren. El simbolismo también resulta evidente en Hojas de algún calendario, en el que la pantalla del ordenador se interpone entre los dos jóvenes protagonistas. Él desea vivir en el mundo real, ella en el mundo virtual. Pero ese simbolismo también está presente en La fiesta. El marco de alegría de una fiesta (la celebración conjunta de un cumpleaños y de un estreno teatral) cobija la caída en picado de un personaje de éxito, su desenmascaramiento ante la sociedad que le cree un artista de talento cuando realmente es un impostor aupado por grupos de poder generados en torno a una maraña de afines intereses. En la jocosa atmósfera, emerge su tragedia personal y se produce su muerte. Los títulos de mis obras son a menudo de un alto contenido simbólico. Ícaros es un ejemplo, protagonizado por 
jóvenes homosexuales que mantienen relaciones en grupo y sin preservativo siguiendo una arriesgada moda que "desafía" la posibilidad de contraer el SIDA. Voracidad de los parques también es otro título extremadamente simbólico, critica los usos y modos de la sociedad actual, sus artificios: el parque contrapuesto al bosque como intento de domesticación de la vida vegetal.

\section{¿Considera que, como creadora, ha contribuido a la redefinición de los} conceptos relacionados con la identidad femenina?

Si lo he conseguido, eso deben juzgarlo los lectores. Por lo menos lo he intentado. En Interiores (desarrollada en los años sesenta) se contraponen dos modelos de mujer. La madre, Carla, y la hija, María, componen una dualidad enfrentada de forma irremediable. La madre: víctima y presa de la educación represora y castradora franquista que la ha convertido en un cero a la izquierda, sacrifica sus propios anhelos y deseos y vive para servir a los demás, para que todos aquellos que la rodean cumplan sus objetivos vitales y alcancen una autorealización que ella nunca obtendrá. Ese personaje es ejemplo de la generación de mujeres que padecieron el franquismo en sus propias carnes. En oposición a ella se encuentra la hija, que reclama su proyección personal como derecho que cree le corresponde por ley natural, que antepone su vida pública y profesional a la vida familiar, el modelo del que se sirve su madre como continuo rasero para calibrarlo todo. En la misma obra, el acto II está protagonizado por María (la hija de Carla) y su hija (Carla, nieta de la anterior Carla), que se desarrolla en los años noventa. La pequeña Carla va creciendo y madurando a lo largo de la escena, en la que hay continuos saltos temporales, y pasa de ser una niña de 7 años a alcanzar la mayoría de edad legal. Sus inquietudes y anhelos, sus descubrimientos (el sexo, la droga, el amor, la responsabilidad...) van sirviendo de materia de reflexión para el espectador. Otro importante campo para la reflexión es el que propicia la madre, María, ahora divorciada y que reaprende a relacionarse con el exterior una vez que su vida de pareja ha finalizado. El redescubrimiento de la vida por parte de María (el sexo de nuevo, el amor, etc...) corre parejo al descubrimiento de la vida que "por vez primera" realiza su hija. 


\section{¿Qué tipo de relaciones interpersonales establecen los personajes de sus obras?}

Suelen ser relaciones complicadas, como crítica y reflejo del enmarañamiento innecesario en el que vive de manera habitual el ser humano en las llamadas "sociedades avanzadas". En Voracidad de los parques, la pareja protagonista es un matrimonio roto cuyos cónyuges continúan conviviendo en el mismo domicilio. Describe una relación enferma en la que la mujer (que padece continuos ataques de celos patológicos) cree estar enamorada de su marido, un marido que la engaña de forma compulsiva con todas las mujeres que conoce como fórmula para adormecer su pánico a la muerte y su necesidad de perdurar en medio de este mundo de futilidad. La ambición personal (su necesidad de obtención de fama y reconocimiento social) cohabita con su voracidad sexual. Los protagonistas de Hojas de algún calendario, se relacionan entre sí a través de internet, en lugar de hacerlo directamente entre ellos. En la obra coral Islas, exploro a través de diferentes escenas conflictos relacionados con la falta de habilidades sociales y comunicativas de los seres humanos, que los convierten en hombres y mujeres aislados a pesar de vivir en compañía. En Esbozo sobre una teoría de las emociones, uno de sus protagonistas, Lucas, es un divorciado que no ha superado su separación. Está enamorado de una joven que le ama, y con la que podría reconstruir su vida, pero es incapaz de confesarle su amor y de zambullirse en una nueva relación por el pánico a volver a fracasar.

\section{En los últimos años se habla continuamente de violencia de género también en} el teatro ¿Está presente en sus textos la violencia de género?

Está presente en varios de mis textos y experimentos dramáticos, como Tolerancia Cero. En Interiores esa presencia es muy clara. La madre (Carla) ha sufrido malos tratos físicos y se culpabiliza a sí misma de las reacciones de su marido, que ella cree haber provocado con su torpeza tal y como le "dictan" las mujeres de su alrededor. También me gusta llevar al escenario la violencia no evidente, el maltrato psicológico, la dominación que no se ejerce por la mera fuerza física. Mario, el protagonista de Voracidad de los parques, maltrata a su esposa, Fabiola. En esta ocasión el maltrato es refinado, alcanza cotas crueles, pero siempre mantiene la elegancia, ya que su estatus social y cultural es 
más elevado que el de los protagonistas de Interiores. Entre él y su mujer va generándose una relación insana, retroalimentada por la angustia vital de ambos personajes que genera dependencia por ambas partes. En mis obras, en general, abunda la violencia.

\section{¿A qué se debe esta prevalencia de la violencia en su teatro?}

Porque la sociedad civilizada es extremadamente violenta, y a mí me gusta reflejar la vida. En muchas ocasiones, alguien me ha dicho: escribes como un hombre, tus obras no parecen escritas por una mujer. Creo que tras ese desafortunado juicio de valor se esconde la percepción de la violencia que late en mis creaciones. En Acoso laboral la crueldad empresarial que sacrifica a los seres humanos en aras del beneficio económico se convierte en protagonista. En Tierra convexa, el protagonista es un asesino en serie de solo mata niños, a los que luego devora. Pero ese personaje, Albert Fish, existió históricamente, vivió en EEUU en el tránsito del siglo XIX al siglo XX. En Fantasmas, sus protagonistas han sufrido abusos sexuales en la infancia a manos de los curas de la parroquia de su barrio. La denuncia la realiza una mujer. Fue una niña pobre, obligada a vivir de las migajas de la caridad de la Iglesia y forzada por lo tanto a callar durante años estos abusos por miedo a ser desplazada socialmente o despreciada por el poderoso aparato de la iglesia y el poder que poseían sobre todo su entorno. ¿Cuántas veces, a lo largo de los últimos años, no hemos constatado que ese problema existía en nuestras sociedades?

\section{¿Qué otras formas de violencia aborda en sus creaciones?}

Hobbes decía que el hombre es un lobo para el hombre, la civilización es la ejercitación de la violencia de forma educada, soterrada. En mis obras, la crítica se multiplica para convertirse en un ataque a la desigualdad social y las lacras que provoca: la pobreza es la forma más primaria de violencia. La pobreza no existe de forma natural, es un estado artificial creado por unos hombres como fórmula para dominar a otros. En ella se encuentra el origen de los abusos de todo tipo, entre ellos los sexuales. En Tu sangre sobre la arena, la protagonista es una niña del llamado Tercer Mundo vendida por su madre a un tratante de mujeres y trasladada al mundo de los ricos, donde termina sus días en la prostitución. Mi obra Deseo está protagonizada por un grupo de corsos sin 
capacidad de inserción en la sociedad francesa, que emplean el robo como forma de vida. Plantea el problema de las minorías dentro de las sociedades avanzadas, esa población marginada y sin posibilidades de asimilación cultural, obligados a vivir fuera de lo establecido. En Apología del amor, que recrea el encuentro de una noche entre una prostituta y un desconocido que demanda sus servicios, la violencia originada por la lucha de clases relega el encuentro sexual a un plano insignificante.

\section{Como creadora, ¿cuál es su objetivo último?}

Que el público reflexione, que engrandezca su horizonte, que vea donde nunca vio y se atreva a llegar a donde nunca llegó. Cortázar decía que hay que tirar la ventana por la ventana. En el acto III de Interiores un padre homosexual se enfrenta a su hijo, que no acepta su forma de vida ni pensamiento. Lo habitual es ver a padres enojados porque sus hijos son homosexuales, pero dándole la vuelta a la tortilla estalla un nuevo combate dialéctico-ideológico. La represión al homosexual la protagoniza el hijo, y la petición de libertad sexual el padre. En Esbozo sobre una teoría de las emociones una pareja de gays reproducen los esquemas de celos, chantaje emocional y control y asfixia al "compañero" que tantas veces hemos presenciado entre las parejas heterosexuales. Que el Arte sirva para transformar el mundo, para mejorar el mundo: ese es mi mayor deseo.

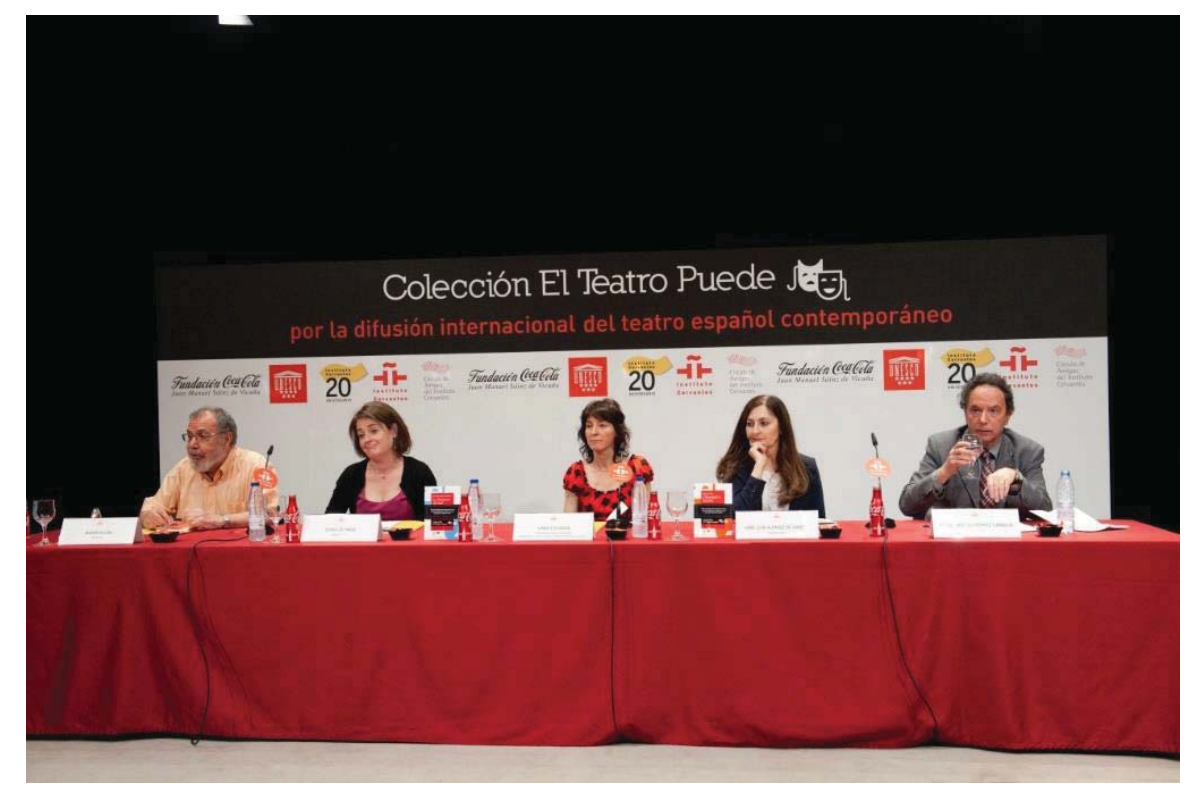

En el Instituto Cervantes, junto a Diana de Paco y otros ponentes. 